\title{
Inulin Measurement
}

National Cancer Institute

\section{Source}

National Cancer Institute. Inulin Measurement. NCI Thesaurus. Code C125945.

The determination of the amount of inulin present in a sample. 